\title{
(6) OPEN ACCESS \\ Probiotics in the prevention of eczema: a randomised controlled trial
}

\author{
Stephen J Allen, ${ }^{1}$ Sue Jordan, ${ }^{2}$ Melanie Storey, ${ }^{1}$ Catherine A Thornton, ${ }^{1}$ \\ Michael B Gravenor, ${ }^{1}$ Iveta Garaiova, ${ }^{3}$ Susan F Plummer, ${ }^{3}$ Duolao Wang, ${ }^{4}$ \\ Gareth Morgan ${ }^{1}$
}

- Additional material is published online only. To view please visit the journal online (http://dx.doi.org/10.1136/ archdischild-2013-305799).

${ }^{1}$ College of Medicine, Swansea University, Swansea, UK

${ }^{2}$ College of Human and Health Sciences, Swansea University,

Swansea, UK

${ }^{3}$ Research and Development Department, Cultech Limited, Port Talbot, UK

${ }^{4}$ Liverpool School of Tropical Medicine, Liverpool, L3 5QA, UK

\section{Correspondence to}

Prof Stephen Allen, Room 314, Grove Building, College of Medicine, Swansea University, Singleton Park, Swansea SA2 8PP, UK;

s.j.allen@swansea.ac.uk

At the time the study was undertaken, IG and SFP were employees of Obsidian Research Ltd, Unit 2 Christchurch Road, Baglan Industrial Park, Port Talbot, West Glamorgan, UK.

Received 11 December 2013 Revised 30 May 2014 Accepted 31 May 2014 Published Online First 19 June 2014

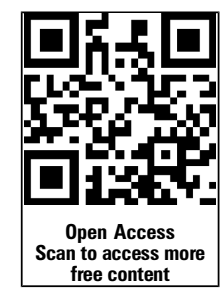

CrossMark

To cite: Allen SJ, Jordan S, Storey $\mathrm{M}$, et al. Arch Dis Child 2014;99:1014-1019.

\section{ABSTRACT \\ Objective To evaluate a multistrain, high-dose probiotic in the prevention of eczema. \\ Design A randomised, double-blind, placebo- controlled, parallel group trial.}

Settings Antenatal clinics, research clinic, children at home.

Patients Pregnant women and their infants. Interventions Women from 36 weeks gestation and their infants to age 6 months received daily either the probiotic (Lactobacillus salivarius CUL61, Lactobacillus paracasei CUL08, Bifidobacterium animalis subspecies lactis CUL34 and Bifidobacterium bifidum CUL20; total of $10^{10}$ organisms/day) or matching placebo.

Main outcome measure Diagnosed eczema at age 2 years. Infants were followed up by questionnaire. Clinical examination and skin prick tests to common allergens were done at 6 months and 2 years.

Results The cumulative frequency of diagnosed eczema at 2 years was similar in the probiotic $(73 / 214,34.1 \%)$ and placebo arms (72/222, 32.4\%; OR $1.07,95 \% \mathrm{Cl}$ 0.72 to 1.6$)$. Among the secondary outcomes, the cumulative frequency of skin prick sensitivity at 2 years was reduced in the probiotic $(18 / 171 ; 10.5 \%)$ compared with the placebo arm (32/173; 18.5\%; OR 0.52, 95\% $\mathrm{Cl} 0.28$ to 0.98 ). The statistically significant differences between the arms were mainly in sensitisation to cow's milk and hen's egg proteins at 6 months. Atopic eczema occurred in $9 / 171(5.3 \%)$ children in the probiotic arm and $21 / 173(12.1 \%)$ in the placebo arm (OR 0.40, 95\% Cl 0.18 to 0.91 ).

Conclusions The study did not provide evidence that the probiotic either prevented eczema during the study or reduced its severity. However, the probiotic seemed to prevent atopic sensitisation to common food allergens and so reduce the incidence of atopic eczema in early childhood.

Trial registration Number ISRCTN26287422.

\section{INTRODUCTION}

The major atopic disorders, eczema, allergic rhinitis and asthma, cause significant disease burdens worldwide. Symptoms of atopy were reported to occur in 15-40\% of children aged 13-14 years living in the UK in the mid-1990s ${ }^{1}$ and prevalence has increased in many countries in recent years. ${ }^{2-4}$

Despite the high atopic disease burden, pathogenic mechanisms remain poorly understood. Atopic disorders are heterogeneous resulting from complex interactions between environmental factors, including exposure to microbes, and host genes modulating innate and acquired immune

\section{What is already known on this topic?}

- Altered exposure to microbial organisms in early life might influence the development of atopy.

- Meta-analysis suggests that probiotics may be effective in the primary prevention of atopy.

\section{What this study adds?}

- Our data do not support use of the study probiotic for the prevention of eczema in early childhood.

- Skin prick sensitivity to common food allergens and atopic eczema were reduced among children receiving the probiotic.

responses, and mucosal and skin integrity. ${ }^{5} \mathrm{~A}$ critical issue is the role of atopy defined as a genetic propensity to develop immunoglobulin $\mathrm{E}$ antibodies following exposure to allergens ${ }^{6}$ and assessed by skin prick tests (SPTs) or measurement of specific IgE in serum. For eczema ${ }^{7}$ and asthma, ${ }^{8}$ atopic sensitisation early in life has been associated with persistent disease.

The hygiene hypothesis, based on the observation of increased atopy in smaller families, ${ }^{9}$ postulates that reduced exposure to infections in early childhood results in aberrant immunological responses to allergens. ${ }^{10}$ Intestinal microbiota provide a critical source of early immune stimulation and variations in early gut colonisation have been associated with the development of atopic disease. ${ }^{11}$ Probiotics are defined as live microorganisms which, when administered in adequate amounts, confer health benefits on the host. ${ }^{12}$ However, the term 'probiotic' is commonly used for microorganisms that are undergoing evaluation for possible health benefits and it is this sense that is used here. Clinical trials suggest a role for probiotics in the primary prevention of atopic eczema. ${ }^{13}$ The mechanisms whereby probiotics may prevent atopy are unclear but might involve reduced exposure to allergens through improved epithelial barrier function and modulation of the developing immune system to prevent IgE sensitisation. ${ }^{14}$

We evaluated the effect of a probiotic comprising two strains of lactobacilli and two strains of bifidobacteria, or an inert placebo, administered to 
mother-infant dyads in the perinatal period on clinical and laboratory manifestations of atopy. Here, we report the clinical manifestations of atopy at age $0-2$ years.

\section{METHODS}

The safety profile of the probiotic ${ }^{15}$ and factors determining compliance with the trial procedures ${ }^{16}$ have been published.

\section{Participants}

Women aged 16 years or more, with a normal singleton pregnancy and intending to give birth at Singleton Hospital, Swansea were invited to join the study. Details of the recruitment process are described elsewhere. ${ }^{16}$ Women with known adverse conditions likely to affect them, the fetus, or the outcome of the pregnancy, were excluded. Women were informed of the trial, by letter, at booking, and provided with further information when attending for antenatal care. Those returning an expression of interest were contacted by researchers. Signed, informed consent was obtained by a researcher at 35-36 weeks gestation.

We had intended to recruit infants at 'high-risk' of developing atopy defined as those with a first degree relative with either asthma or eczema diagnosed by a health professional or allergic rhinitis treated by a doctor. ${ }^{17}$ However, sufficient details of atopy in first degree relatives were often difficult to obtain at recruitment. Therefore, in practice, infants with and without an increased risk of atopy were recruited. To preserve the integrity of the random allocation sequence, all infants are included in this report. Key findings relating to those at increased risk of atopy are presented in Webtable 1 .

\section{Randomisation}

Pregnant women were allocated on a 1:1 basis at 36 weeks gestation to either the active or placebo arm of the study according to a computer-generated, random sequence without blocks. The random sequence was generated by the commercial partners and held independently of the research team. Women were allocated consecutively to the next number in the randomisation sequence and provided with the corresponding, preprepared intervention pack.

\section{Intervention}

We selected a multispecies probiotic preparation on the basis of greater efficacy than either single species or single organism preparations in the prevention or treatment of diseases in animal models and clinical trials. ${ }^{18}$ Species that had been evaluated in previous clinical trials, including the prevention of eczema were selected. ${ }^{17}$ Organisms were selected on the basis of activity in promoting responses in vitro consistent with protection against allergy (personal communication; Dr S. Plummer 2003).

The active intervention comprised a vegetarian capsule containing Lactobacillus salivarius CUL61 (National Collection of Industrial, Food and Marine Bacteria (NCIMB) 30211) $6.25 \times 10^{9}$ colony forming units (CFUs), Lactobacillus paracasei CUL08 (NCIMB 30154) $1.25 \times 10^{9}$ CFUs, Bifidobacterium animalis subspecies lactis CUL34 (NCIMB 30172) $1.25 \times 10^{9}$ CFUs and Bifidobacterium bifidum CUL20 (NCIMB 30153) $1.25 \times 10^{9}$ CFUs as a freeze-dried powder. Organism identity was confirmed at the species and strain levels by $16 \mathrm{~S}$ rRNA gene sequencing, rep PCR fingerprinting and cluster analysis, and Random Amplified Polymorphic DNA typing. Women in the placebo arm received capsules of identical appearance containing maltodextrin powder. The dose in both arms was one capsule daily from 36 weeks gestation until delivery. Infants received the same capsules as their mother once daily from birth to age 6 months. Women were asked to store the capsules in the fridge and either took the capsule by mouth or sprinkled the contents onto food. The contents of the capsule were sprinkled directly into the infant's open mouth or mixed with expressed breast milk or formula feed. Mothers were asked not to consume any commercially available probiotics or live yoghurts or administer these to their infants.

Unused capsules returned by participants from intervention and placebo groups for compliance monitoring were tested by an independent laboratory on an opportunistic basis. No live bacteria were identified in the placebo capsules, conforming with the random allocation sequence. Viability of the bacteria in the active preparation was consistent with the storage conditions confirming no significant deterioration in the product.

\section{Data collection and allergen testing}

Demographic information and possible risk factors for atopy were recorded at recruitment. Follow-up questionnaires were scheduled every 6 weeks to age 6 months and at 1 year and 2 years. A research assistant completed questionnaires with the parent/carer during a home visit at age 6 weeks, during research clinics at 6 months and 2 years and by telephone interview at other times. Where a follow-up was missed, parents/carers were asked to provide information for the period since the last questionnaire was completed. Questionnaires recorded any atopic disorders diagnosed by health professionals, treatments received and the occurrence and duration of common skin, respiratory and gastrointestinal symptoms.

At research clinics, infants were examined by either a clinician or a trained researcher. If present, the severity of eczema was evaluated by the scoring atopic dermatitis index. ${ }^{19}$ SPTs using common food allergens (cow's milk, hen's egg), aeroallergens (house dust mite, cat dander, grass pollen) and positive (histamine) and negative controls were performed. The response to an allergen was considered positive if there was a wheal diameter $\geq 3 \mathrm{~mm} .^{20}$

\section{Outcome measures}

The primary outcome was the cumulative frequency of diagnosed eczema at 2 year follow-up (reported by parents/carers to have been diagnosed by a health professional or diagnosed during a research clinic). Eczema was defined as an itchy rash affecting the face, scalp or extensor surfaces of the limbs in infants and flexures in older children and of duration $\geq 4$ weeks and with $\geq 1$ exacerbation by age 24 months $^{21}$ based on the information from questionnaires. Secondary outcomes were responses to SPTs, atopic eczema defined as eczema with one or more positive SPTs, eczema of any duration and whether or not diagnosed by a health professional, the severity of eczema, treatment with topical steroid preparations, respiratory symptoms with asthma and allergic rhinitis and reported food allergy. We had intended to report outcomes up to age 2 years. However, scheduled follow-up assessments were often delayed particularly when mothers had returned to work. Therefore, we have included all information for children aged up to, but not including, 3 years.

\section{Data management and analysis}

Strict blinding of the clinical research teams regarding participant allocation was maintained until after databases were locked following completion of data collection. The period of follow-up, defined as the time from birth to the age of the last follow-up questionnaire, was calculated for each infant. 
Table 1 Demographic characteristics and possible risk factors for atopy at baseline

\begin{tabular}{|c|c|c|}
\hline Variable & Probiotic arm* & Placebo arm* \\
\hline $\begin{array}{l}\text { Socioeconomic status (Townsend } \\
\text { rank; N; median, IQR) }\end{array}$ & 220; 949 (333-1514) & $234 ; 864$ (330-1558) \\
\hline $\begin{array}{l}\text { Mother smoked during } \\
\text { pregnancy }\end{array}$ & $41 / 205(20.0 \%)$ & $47 / 218(21.6 \%)$ \\
\hline Vaginal delivery & $152 / 216(70.4 \%)$ & $157 / 232(67.7 \%)$ \\
\hline \multicolumn{3}{|l|}{ House } \\
\hline $\begin{array}{l}\text { Cat, dog, rodent or bird kept } \\
\text { indoors }\end{array}$ & $112 / 220(50.9 \%)$ & $120 / 234(51.3 \%)$ \\
\hline $\begin{array}{l}\text { Damp and/or mould as } \\
\text { reported by participants }\end{array}$ & $59 / 217(27.2 \%)$ & $56 / 232(24.1 \%)$ \\
\hline \multicolumn{3}{|l|}{ No. households with } \\
\hline 1 adult & $10 / 220(4.6 \%)$ & $9 / 234(3.9 \%)$ \\
\hline$\geq 3$ adults & $20 / 220(9.1 \%)$ & $25 / 234(10.7 \%)$ \\
\hline no other children & $81 / 220(36.8 \%)$ & $93 / 234(39.7 \%)$ \\
\hline$\geq 3$ other children & $16 / 220(7.3 \%)$ & $18 / 234(7.7 \%)$ \\
\hline $\begin{array}{l}\text { No. infants at increased risk of } \\
\text { atopy } \dagger\end{array}$ & $197 / 220(89.6 \%)$ & $205 / 234(87.6 \%)$ \\
\hline \multicolumn{3}{|c|}{$\begin{array}{l}\text { This table gives the number of participants (\%) unless otherwise stated. } \\
\text { *Denominator varies according to information provided by parents/carers and } \\
\text { compliance with follow-up. } \\
\text { †Defined as first degree relative with either asthma or eczema diagnosed by a health } \\
\text { professional or allergic rhinitis treated by a doctor. }\end{array}$} \\
\hline
\end{tabular}

Demographic variables, possible risk factors for atopy, and primary and secondary outcomes were analysed by treatment allocated. Findings for binary outcomes were expressed in ORs with $95 \%$ CIs. A $\chi^{2}$ test or Fisher's exact test was used to compare proportions. Continuous outcome variables had skewed distributions and were summarised using median values and IQR and compared by the Mann-Whitney U test.

We performed adjusted analyses to investigate whether the trends in atopic sensitivity or atopic eczema were modified by baseline demographic variables (table 1), possible risk factors for atopy (table 2) and mother and infant compliance. For compliance, participants were classified as no compliance and compliance levels 1-4 representing the quartiles of the total number of days that trial interventions were taken. We used a set of logistic regression models, including the study treatment in each case and adding the other variables in a stepwise manner, retaining them in the model if they resulted in a significant improvement in model fit (at the 5\% level). Analysis was performed using R/SPSS V.16.0 (IBM, USA)/SAS V.9.2 (SAS Institute, USA).

Sample size

We aimed to recruit sufficient mother/infant dyads to observe a $50 \%$ reduction in the frequency of asthma by age 5 years from

Table 2 Potential modulating factors for atopy during follow-up

\begin{tabular}{lcc}
\hline Variable & Probiotic arm & Placebo arm \\
\hline Breast fed (full or partial)—any duration & $49 / 191(25.7 \%)$ & $47 / 205(22.9 \%)$ \\
Age last breast fed in months (N; & $185 ; 1[0-7]$ & $190 ; 1[0-5]$ \\
median, (IQR)) & & \\
Attended child-minder in first 12 months & $10 / 163(6.1 \%)$ & $16 / 172(9.3 \%)$ \\
Attended nursery in first 12 months & $65 / 162(40.1 \%)$ & $61 / 170(35.9 \%)$ \\
Any oral/systemic antibiotics & $155 / 214(72.4 \%)$ & $154 / 225(68.4 \%)$ \\
\hline
\end{tabular}

This table gives the number of participants (\%) unless otherwise stated.
$20 \%$ to $10 \% .^{22}$ For the purposes of this paper, we expected that $40 \%$ of infants at increased risk of atopy (defined as having a first degree relative with an atopic condition) in the placebo arm would have developed eczema by age 2 years. ${ }^{17} 23$ A total of 308 infants (154 in each arm) would be sufficient to detect a $50 \%$ reduction in eczema frequency from $40 \%$ in the control arm to $20 \%$ in the probiotic arm with $90 \%$ power at the $1 \%$ significance level.

\section{Role of the funding source}

Cultech UK advised on study design, provided the trial interventions and generated the random allocation sequence but was not involved in data collection, analysis or interpretation of the findings.

\section{Ethics approval}

The study was approved by the local research ethics committee in February 2004 and registered with Current Controlled Trials (ISRCTN26287422).

\section{RESULTS}

\section{Participants}

Recruitment began in May 2005 and the last scheduled 2 year contact was in November 2009. Of 1419 women attending antenatal clinics who had expressed an interest in the study, 454 were recruited and randomised (figure 1; Trial profile).

Demographic variables and possible risk factors for atopy were similar in the 220 women randomised to the probiotic

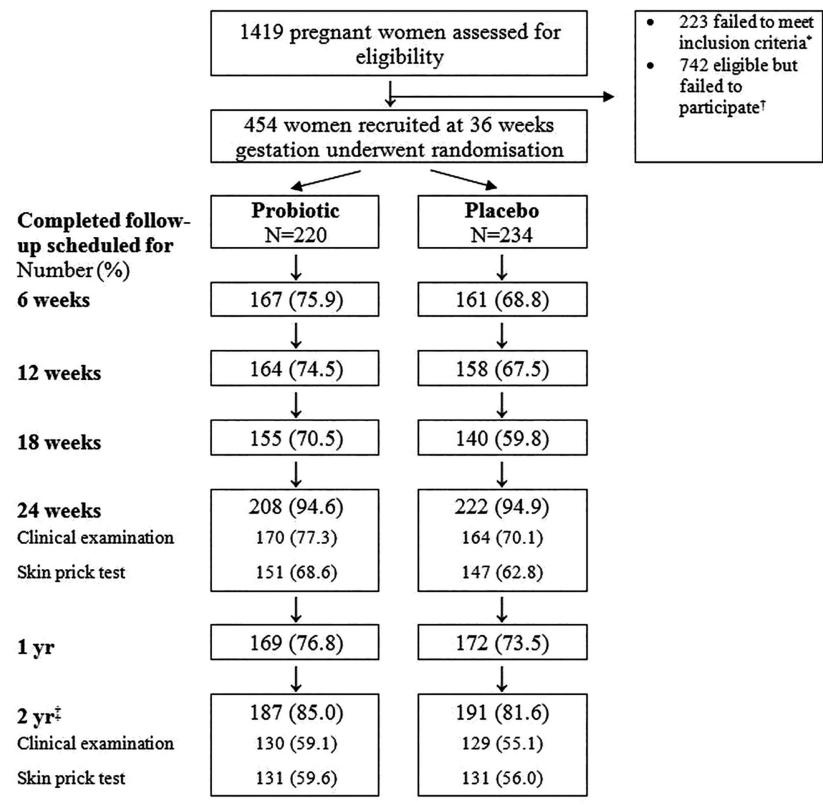

Figure 1 Trial profile * Reasons for exclusion: pregnancy complication $(n=110)$; presented after 36 weeks gestation or at the end of the recruitment period and before 36 weeks gestation (83); multiple pregnancy (14); contacted again after recruitment terminated (9); previous infant participated in trial (6); unwilling to stop current probiotic (1). tReasons for failure to participate: lost contact with research team (288); not sufficiently interested or disliked tests (184); concern that trial was "too much to take on" (129); unwillingness to take the investigation products (85); not prepared to be allocated to the placebo arm (21); developed a medical condition (16); language difficulties (10); not willing for this child to be treated differently from previous child (7); bereavement (2). ‡Follow-up was often delayed; includes children seen up to, but not including, age 3 years. 
arm and 234 to the placebo arm (table 1). Maternal smoking during pregnancy, keeping pets and houses affected by damp or mould were common in both arms. Three hundred and seventyfour women were carrying an infant at high risk of developing atopy with a similar proportion in each study arm (table 1). Potential modifying factors for atopy during follow-up, such as feeding practice, exposure to other people and to antibiotics, were also similar in the two arms (table 2).

Completion of questionnaires and attendance at research clinics was similar in the two arms (figure 1). Median (IQR) age at follow-up was 2.11 years $(2.01-2.28$ years) in the probiotic arm and 2.09 years (2.01-2.24 years) in the placebo arm $(p=0.28)$. We have reported previously that follow-up was more complete among less deprived families and mothers who were non-smokers.

The trial arm was not associated with retention or clinic attendance at 24 weeks and 2 years. ${ }^{16}$

\section{Primary outcome measure}

The cumulative frequency of diagnosed eczema (a composite of carers' reports and research clinic findings) at 2 years was similar in the probiotic $(73 / 214 ; 34.1 \%)$ and placebo arms (72/222, 32.4\%; OR 1.07, 95\% CI 0.72 to $1.6 ; \mathrm{p}=0.71)$.

\section{Secondary outcome measures}

Positive SPTs to one or more common allergens at either age 6 months or 2 years were significantly less frequent in the probiotic arm (OR 0.52, 0.28-0.98; $\mathrm{p}=0.036$, table 3). The number needed to treat to prevent one infant becoming sensitised was 13 (95\% CI 7 to 173). The reduced skin prick responses in the probiotic arm were mainly to food allergens (cow's milk and egg proteins) and statistically significant differences were already apparent at age 6 months. In contrast, sensitisation to aeroallergens (house dust mite, cat dander and grass pollen) occurred mainly after 6 months and was similar in the two arms (table 3).

Atopic eczema at 2 years was significantly less frequent in the probiotic arm (OR 0.40, 0.18-0.91; $\mathrm{p}=0.024)$ and was apparent by age 6 months (table 3). Differences between the two groups in non-SPT positive eczema were not statistically significant. At age 6 months, non-SPT positive eczema occurred in 37/ $147(25.2 \%)$ children in the probiotic and 24/143 (16.8\%) in the placebo arm $\left(\chi^{2}=3.06 ; \mathrm{p}=0.08\right)$. At age 2 years, non-SPT positive eczema occurred in 57/171 (33.3\%) children in the probiotic and $46 / 173(26.6 \%)$ in the placebo arm $\left(\chi^{2}=1.86\right.$; $\mathrm{p}=0.17)$. The cumulative frequency of all eczema to age 2 years reported by parents and carers, whether or not diagnosed by a

Table 3 Secondary outcomes according to intervention group

\begin{tabular}{|c|c|c|c|c|}
\hline Variable & Probiotic arm & Placebo arm & OR $(95 \% \mathrm{Cl})$ & p Value* \\
\hline SPT† positive at $6 \mathrm{~m}$ & $6 / 151(3.97 \%)$ & $16 / 147(10.88 \%)$ & 0.34 (0.13 to 0.89$)$ & 0.023 \\
\hline - cow's milk & $0 / 148(0.0 \%)$ & $5 / 147(3.40 \%)$ & - & $0.030^{*}$ \\
\hline$>$ egg & $5 / 148(3.4 \%)$ & $14 / 147(9.5 \%)$ & $0.33(0.11$ to 0.95$)$ & 0.032 \\
\hline - house dust mite & $1 / 151(0.66 \%)$ & $0 / 147(0.0 \%)$ & - & $0.51^{*}$ \\
\hline$\checkmark$ cat & $0 / 151(0.0 \%)$ & $2 / 145(1.4 \%)$ & - & $0.24^{*}$ \\
\hline grass & $1 / 150(0.67 \%)$ & $0 / 147(0.0 \%)$ & - & $0.49 *$ \\
\hline SPT ${ }^{\prime}$ positive at either $6 \mathrm{~m}$ or $2 \mathrm{yrs}$ & $18 / 171(10.5 \%)$ & $32 / 173(18.5 \%)$ & 0.52 (0.28 to 0.98$)$ & 0.036 \\
\hline cow's milk & $1 / 171(0.6 \%)$ & $6 / 173(3.5 \%)$ & $0.16(0.02$ to 1.4$)$ & $0.12^{*}$ \\
\hline$\triangleright$ egg & $9 / 171(5.3 \%)$ & $19 / 173(11.0 \%)$ & $0.45(0.2$ to 1.0$)$ & 0.052 \\
\hline - house dust mite & $9 / 171(5.3 \%)$ & $11 / 173(6.4 \%)$ & $0.82(0.3$ to 2.0$)$ & 0.66 \\
\hline$\checkmark$ cat & $3 / 171(1.8 \%)$ & $7 / 173(4.0 \%)$ & $0.42(0.1$ to 1.7$)$ & 0.20 \\
\hline - grass & $2 / 171(1.2 \%)$ & $2 / 173(1.2 \%)$ & $1.0(0.14$ to 7.2$)$ & $0.99 *$ \\
\hline \multicolumn{5}{|l|}{ Skin } \\
\hline - Atopic eczema at $6 \mathrm{~m}$ & $4 / 151(2.7 \%)$ & $13 / 147(8.8 \%)$ & $0.28(0.089$ to 0.88$)$ & 0.021 \\
\hline - Severity of eczema at 6 m clinic $\neq$; median, (IQR) & $14.3(7.5-17.9)$ & $14.4(10.6-24.9)$ & - & 0.46 \\
\hline Atopic eczema at 2 yrs & $9 / 171(5.3 \%)$ & $21 / 173(12.1 \%)$ & $0.40(0.18$ to 0.91$)$ & 0.024 \\
\hline - Severity of eczema at $2 \mathrm{yr}$ clinic $\neq$; median (IQR) & $11.1(7.2-20.1)$ & $14.2(7.2-14.2)$ & - & 0.85 \\
\hline - All reported eczema§, 9 & $119 / 214(55.6 \%)$ & $132 / 226(58.4 \%)$ & $0.90(0.61$ to 1.3$)$ & 0.55 \\
\hline - Received topical steroid preparation & $30 / 214(14.0 \%)$ & $40 / 226(17.7 \%)$ & $0.76(0.45$ to 1.2$)$ & 0.29 \\
\hline \multicolumn{5}{|l|}{ Respiratory } \\
\hline All reported asthmaף & 23/171 (11.9\%) & $20 / 179(10.0 \%)$ & $1.2(0.63$ to 2.3$)$ & 0.57 \\
\hline - Night-time cough & $156 / 214(72.9 \%)$ & $164 / 226(72.6 \%)$ & $1.0(0.67$ to 1.5$)$ & 0.93 \\
\hline Night-time or daytime cough & $178 / 214(83.2 \%)$ & $188 / 226(83.2 \%)$ & $1.0(0.6$ to 1.6$)$ & 0.99 \\
\hline Wheezing without symptoms of a virus infection & $50 / 214(23.4 \%)$ & $55 / 171(24.3 \%)$ & $0.95(0.61$ to 1.47$)$ & 0.81 \\
\hline Inhaled bronchodilator or steroid & $26 / 214(12.1 \%)$ & $27 / 226(11.9 \%)$ & $1.0(0.57$ to 1.8$)$ & 0.94 \\
\hline - Allergic rhinitis & $10 / 190(5.3 \%)$ & $10 / 201(5.0 \%)$ & $1.1(0.43$ to 2.6$)$ & 0.90 \\
\hline - Sneezing and/or snuffling & $207 / 214(96.7 \%)$ & $212 / 226(93.8 \%)$ & $1.95(0.77$ to 4.93$)$ & 0.15 \\
\hline Any reported food allergy & $22 / 200(11.0 \%)$ & $31 / 204(15.2 \%)$ & 0.69 (0.38 to 1.2$)$ & 0.21 \\
\hline
\end{tabular}

This table gives the number of participants (\%) unless otherwise stated.

${ }^{*} \chi^{2}$ test for contingency tables or Fisher's exact test* where expected values in cells were $<5$.

tSPT valid if diameter of wheal for the positive control was $\geq 1 \mathrm{~mm}$ than diameter for the negative control; SPT positive if diameter of wheal for antigen was $\geq 3 \mathrm{~mm}$ than diameter for negative control.

‡SCORAD index ${ }^{19}$

$\S 0 f$ any duration.

IWhether or not diagnosed by a health professional.

SCORAD, scoring atopic dermatitis; SPT, skin prick test. 
health professional, its severity, the duration of rash and the use of topical steroids were similar in the two arms. The cumulative frequency of asthma and allergic rhinitis and symptoms and treatments consistent with these conditions and of reported food allergy were also similar in both arms (table 3).

The differences between the two arms in the risk of atopic eczema and SPT positivity among infants with one or more relatives with atopy were very similar to those in the whole cohort (webtable 1). However, with the exception of reduced sensitivity to cow's milk protein at 6 months, differences in the smaller cohort did not reach statistical significance. Median (IQR) compliance with the trial interventions in pregnant women was 20 (12-28) days in the probiotic arm and 20 (12-28) days in the placebo arm $(p=0.98$, Mann-Whitney $U$ test). In infants, the corresponding values were 106 (30-141) days and 103 (11$151)$ days $(p=0.97$, Mann-Whitney $U$ test). In logistic regression analyses, in almost all cases, additional variables (table 1) were not significantly related to clinical outcomes and did not change the estimated OR for the effect of the probiotic. The exception was the presence of a smoker in the household; this was a significant risk factor for atopic eczema and atopic sensitivity (OR at 2 years: $2.48,95 \%$ CI 1.08 to $5.70 ; \mathrm{p}=0.033$ and OR 2.25, $95 \%$ CI 1.16 to $4.37 ; \mathrm{p}=0.017$ respectively). This effect was independent of the treatment and did not significantly modify the univariate OR for the treatment effect. There was no evidence for an interaction effect between smoking and treatment allocation.

We have reported previously that probiotic administration was not associated with adverse effects in either mothers or their infants. ${ }^{15}$

\section{DISCUSSION}

Our findings do not support the administration of a multistrain, high-dose probiotic to mothers during late pregnancy and their infants from birth to age 6 months for the prevention of eczema in early childhood. However, probiotic administration was associated with a reduced frequency in sensitivity to food antigens and atopic eczema.

The strengths of our study are the relatively large number of mother-infant dyads recruited, the pragmatic nature of the trial, and confirmation of identity and viability of the probiotic organisms.

The study had several weaknesses. We had intended to evaluate clinical outcomes in infants at increased risk of atopy identified by having one or more first degree relatives with atopy. In practice, this was difficult to determine accurately at recruitment. However, the frequency of atopy and effects of the probiotic were similar in infants with and without a first degree relative with atopy. We expected that administering a novel intervention to healthy young infants would be difficult and, although compliance with the trial interventions in mothers was good, compliance was lower in infants. Finally, many mothers returned to work and this resulted in missed or delayed follow-up questionnaires and study clinic attendances. Although we compensated for missed follow-ups by subsequently asking parents and carers for information since the last assessment was done, this may have resulted in some loss of accuracy of information.

Our finding that the study probiotic did not affect the frequency of eczema is inconsistent with a meta-analysis of 13 randomised, placebo-controlled trials (3092 infants/children), where probiotic administration was associated with modest reductions in the frequency of eczema (fixed effects analysis; RR 0.79; 95\% CI 0.71 to 0.88$).{ }^{24}$ Despite agreement between studies in the meta-analysis $\left(\mathrm{I}^{2}=24.0 \%\right),{ }^{24}$ variability in outcomes between studies are likely to result from differences in the probiotics used, ${ }^{25}$ the contribution of atopic and other pathogenic factors including variations in host mucosal and skin integrity, ${ }^{5} 6$ the diagnostic criteria, and outcome measures used for eczema. ${ }^{27}$

Our observations of reduced frequency of skin prick sensitivity to food allergens and eczema in children with demonstrated allergic sensitivity in the probiotic arm are consistent with those of a meta-analysis (20 cohorts; 4031 participants, including our findings) where probiotic administration during infancy and childhood was associated with reduced serum IgE and atopic sensitisation to food or inhalant allergens in random effects analysis with limited heterogeneity between studies and without

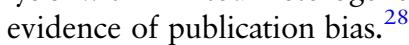

In our study, in contrast to food allergens, sensitivity to aeroallergens was similar in the two arms. This tends to develop after infancy $^{29}$ and, with the exception of two studies, ${ }^{30} 31$ most researchers have also reported that probiotic administration during early infancy did not reduce aeroallergen sensitivity. ${ }^{25}$ 32-39 Our observation that probiotic administration did not reduce the frequency of asthma or wheeze in young children is consistent with other studies. $^{28}$

\section{CONCLUSION}

Administration of probiotics in early life may have a role in the prevention of atopic sensitisation. However, a better understanding of strain-specific probiotic effects ${ }^{25} 40$ and how these address underlying atopic mechanisms is needed to guide the selection of strains for evaluation in clinical trials. Long-term follow-up to determine the effect of probiotic administration on the allergic march is also a priority. ${ }^{41}$

Acknowledgements The authors thank the children and their parents for partaking in this study; Drs Mike Cosgrove and Jean Matthes for comments on the final manuscript; Alyson James for help with skin prick tests.

Contributors SJA, SJ, CAT, MBG, SFP, DW and GM conceived and designed the study. SJA, SJ, GM acquired the data. MBG and DW performed the data analysis and SJA, SJ, CAT, MBG, SFP, DW and GM interpreted the findings. SJA wrote the initial draft. All authors contributed to the interpretation of the data, revised the article critically for important intellectual content and gave final approval of the version to be published.

Funding Knowledge Exploitation Fund, Collaborative Industrial Research (project no. HEO9 COL 1002), Welsh Development Agency, UK. Cultech, UK part-funded the research and provided the interventions.

Competing interests SFP is a Director of Cultech. IG reports grants from Cultech UK, during the conduct of the study. SJA reports a grant from Yakult UK outside the submitted work. The remaining authors declare that they have no competing interests.

\section{Patient consent Obtained.}

Ethics approval Swansea local research ethics committee.

Provenance and peer review Not commissioned; externally peer reviewed.

Data sharing statement The authors welcome others who may be interested in their unpublished data to contact the corresponding author.

Open Access This is an Open Access article distributed in accordance with the Creative Commons Attribution Non Commercial (CC BY-NC 3.0) license, which permits others to distribute, remix, adapt, build upon this work non-commercially, and license their derivative works on different terms, provided the original work is properly cited and the use is non-commercial. See: http://creativecommons.org/ licenses/by-nc/3.0/

\section{REFERENCES}

1 ISAAC. Worldwide variation in prevalence of symptoms of asthma, allergic rhinoconjunctivitis, and atopic eczema: ISAAC. The International Study of Asthma and Allergies in Childhood (ISAAC) Steering Committee. Lancet 1998;351:1225-32. 
2 Asher Ml, Montefort S, Björkstén B, et al. Worldwide time trends in the prevalence of symptoms of asthma, allergic rhinoconjunctivitis, and eczema in childhood: ISAAC Phases One and Three repeat multicountry cross-sectional surveys. Lancet 2006;368:733-43.

3 Odhiambo JA, Williams HC, Clayton TO, et al. Global variations in prevalence of eczema symptoms in children from ISAAC Phase Three. J Allergy Clin Immunol 2009;124:1251-8.

4 Flohr C. Recent perspectives on the global epidemiology of childhood eczema. Allergol Immunopathol (Madr) 2011;39:174-82.

5 Bieber T. Atopic dermatitis. Ann Dermatol 2010;22:125-37.

6 Arshad SH, Tariq SM, Matthews S, et al. Sensitization to common allergens and its association with allergic disorders at age 4 years: a whole population birth cohort study. Pediatrics 2001;108:E33.

7 Wüthrich B, Schmid-Grendelmeier P. The atopic eczema/dermatitis syndrome. Epidemiology, natural course, and immunology of the IgE-associated ("extrinsic") and the nonallergic ("intrinsic") AEDS. J Investig Allergol Clin Immunol 2003;13:1-5.

8 Illi S, von Mutius E, Lau S, et al. Perennial allergen sensitisation early in life and chronic asthma in children: a birth cohort study. Lancet 2006;368:763-70.

9 Strachan DP. Hayfever, hygiene and household size. BMJ 1989;299:1259-60.

10 Okada H, Kuhn C, Feillet $H$, et al. The 'hygiene hypothesis' for autoimmune and allergic diseases: an update. Clin Exp Immunol 2010;160:1-9.

11 Yoo J, Tcheurekdjian $\mathrm{H}$, Lynch SV, et al. Microbial manipulation of immune function for asthma prevention: inferences from clinical trials. Proc Am Thorac Soc 2007:4:277-82.

12 FAO/WHO. Report on Joint FAO/WHO Expert Consultation on Evaluation of Health and Nutritional Properties of Probiotics in Food Including Powder Milk with Live Lactic Acid Bacteria. 2001. ftp://ftp.fao.org/es/esn/food/probio_report_en.pdf (accessed Sep 2013).

13 Tang ML, Lahtinen SJ, Boyle RJ. Probiotics and prebiotics: clinical effects in allergic disease. Curr Opin Pediatr 2010;22:626-34.

14 Ozdemir 0 . Various effects of different probiotic strains in allergic disorders: an update from laboratory and clinical data. Clin Exp Immunol 2010;160:295-304.

15 Allen SJ, Jordan S, Storey M, et al. Dietary supplementation with lactobacilli and bifidobacteria is well tolerated and not associated with adverse events during late pregnancy and early infancy. J Nutr 2010;140:483-8.

16 Jordan S, Watkins A, Storey M, et al. Volunteer bias in recruitment, retention, and blood sample donation in a randomised controlled trial involving mothers and their children at six months and two years: a longitudinal analysis. PLOS ONE 8: e67912.

17 Kalliomäki M, Salminen S, Arvilommi $H$, et al. Probiotics in the primary prevention of atopic disease: a randomised placebo-controlled trial. Lancet 2001;357:1076-9.

18 Timmerman HM, Koning CJ, Mulder L, et al. Monostrain, multistrain and multispecies probiotics - A comparison of functionality and efficacy. Int J Food Microbiol 2004;96:219-33.

19 Kunz B, Oranje AP, Labrèze L, et al. Clinical validation and guidelines for the SCORAD index: consensus report of the European Task Force on Atopic Dermatitis. Dermatology 1997;195:10-9.

20 Position paper: allergen standardization and skin tests. The European academy of allergology and clinical immunology. Allergy 1993;48:48-82.

21 Leung DY, Bieber T. Atopic dermatitis. Lancet 2003;361:151-60.

22 Kaur B, Anderson HR, Austin J, et al. Prevalence of asthma symptoms, diagnosis, and treatment in 12-14 year old children across Great Britain (international study of asthma and allergies in childhood, ISAAC UK). BMJ 1998;316:118-24.
23 Wadonda-Kabondo N, Sterne JAC, Golding J, et al. A prospective study of the prevalence and incidence of atopic dermatitis in children aged 0-42 months. $\mathrm{Br} J$ Dermatol 2003;149:1023-8.

24 Pelucchi C, Chatenoud L, Turati F, et al. Probiotics supplementation during pregnancy or infancy for the prevention of atopic dermatitis: a meta-analysis. Epidemiology 2012;23:402-14.

25 Wickens K, Black PN, Stanley TV, et al. A differential effect of 2 probiotics in the prevention of eczema and atopy: a double-blind, randomized, placebo-controlled trial. J Allergy Clin Immunol 2008;122:788-94.

26 Fiocchi A, Burks W, Bahna SL, et al. Clinical use of probiotics in pediatric allergy (CUPPA): a world allergy organization position paper. World Allergy Organ J 2012:5:148-67.

27 Flohr C. Atopic dermatitis diagnostic criteria and outcome measures for clinical trials: still a mess. J Invest Dermatol 2011;131:557-9.

28 Elazab N, Mendy A, Gasana J, et al. Probiotic administration in early life, Atopy, and Asthma: a meta-analysis of clinical trials. Pediatrics 2013;132:e666-76.

29 Kulig M, Bergmann R, Klettke $U$, et al. Natural course of sensitization to food and inhalant allergens during the first 6 years of life. J Allergy Clin Immunol 1999;103:1173-9.

30 Abrahamsson TR, Jakobsson T, Bottcher MF, et al. Probiotics in prevention of IgE-associated eczema: a double-blind, randomized, placebo-controlled trial. $J$ Allergy Clin Immunol 2007;119:1174-80.

31 Rose MA, Stieglitz F, Köksal A, et al. Efficacy of probiotic Lactobacillus GG on allergic sensitization and asthma in infants at risk. Clin Exp Allergy 2010;40:1398-405.

32 Boyle RJ, Ismail IH, Kivivuori S, et al. Lactobacillus GG treatment during pregnancy for the prevention of eczema: a randomized controlled trial. Allergy 2011:66:509-16

33 Soh SE, Aw M, Gerez I, et al. Probiotic supplementation in the first 6 months of life in at risk Asian infants-effects on eczema and atopic sensitization at the age of 1 year. Clin Exp Allergy 2009;39:571-8

34 Kopp MV, Hennemuth I, Heinzmann A, et al. Randomized, double-blind, placebo-controlled trial of probiotics for primary prevention: no clinical effects of Lactobacillus GG supplementation. Pediatrics 2008:121:e850-6.

35 Taylor AL, Dunstan JA, Prescott SL. Probiotic supplementation for the first 6 months of life fails to reduce the risk of atopic dermatitis and increases the risk of allergen sensitization in high-risk children: a randomized controlled trial. J Allergy Clin Immunol 2007;119:184-91.

36 Kalliomaki M, Salminen S, Poussa T, et al. Probiotics and prevention of atopic disease: 4-year follow-up of a randomised placebo-controlled trial. Lancet 2003:361:1869-71.

37 Kukkonen K, Savilahti E, Haahtela T, et al. Probiotics and prebiotic galacto-oligosaccharides in the prevention of allergic diseases: a randomized, double-blind, placebo-controlled trial. J Allergy Clin Immunol 2007;119:192-8.

38 Niers L, Martin R, Rijkers $G$, et al. The effects of selected probiotic strains on the development of eczema (the PandA study). Allergy 2009;64:1349-58.

39 West $\mathrm{CE}$, Hammarström ML, Hernell 0 . Probiotics during weaning reduce the incidence of eczema. Pediatr Allergy Immunol 2009;20:430-7.

40 Kalliomäki M, Antoine JM, Herz U, et al. Guidance for substantiating the evidence for beneficial effects of probiotics: prevention and management of allergic diseases by probiotics. J Nutr 2010;140:713S-21S.

41 Ker J, Hartert TV. The atopic march: what's the evidence? Ann Allergy Asthma Immunol 2009;103:282-9. 